\title{
218DE BESTUURSVERGADERING,
}

GEHOUDEN 26 FEBRUARI 1881.

Tegenwoordig de heeren van Rappard (Voorzitter), Kniphorst (Penningmeester), Wijnmalen (Secretaris), Corns. de Groot, van der Gon Netseher, Lammers van Toorenburg, Quarles van Ufford, Robidé van der Aa, Kern, Meinsma en Juynboll. Afwezig de heer van Goltstein, met kennisgeving.

De notulen van het verhandelde in de vorige Vergadering worden gelezen en goedgekeurd.

Naar aanleiding van het in de notulen voorkomend be richt van het overlijden van het verdienstelijk corresponderend lid, P. A. Leupe, uit de heer Quarles van Ufford den wensch dat er voor de Bijdragen een beknopt levensbericht vin gemeld Medelid, met toevoeging eener zoo volledig moge lijke lijst zijner vele geschriften, moge worden samengesteld.

De Secretaris verklaart zich bereid die taak op zich te nemen.

De Voorzitter deelt mede, dat is ingekomen:

$a$ eene missive van de Koninklijke Akademie van Weten. schappen te Amsteraiam, ten geleide van éen exemplaar der laatst uitgekomen geschriften.

$b$. eene tweede missive van evengemelde instelling, houdende dankbetuiging voor de toezending der Bijdragen van het Instituut.

Beide missives worden voor kennisgeving aangenomen.

c. eene missive van den heer P. E. Teding van Berkhout, te Amsterdam, houdende mededeeling dat zijn broeder, mr. J. J. Teding van Berkhout, overleden is.

Hiervan zal aanteekeniag worden gehouden.

Door den Secretaris wordt ter tafel gebracht een door hem van Commissarissen in Indië ontvangen bijdrage des heeren J. Habbema over het Manangkabosch ter plaatsing in de Bijdragen van het Instituut. Om bericht en raad in handen gesteld der hceren Juynboll en Meinsma. 
Aan de orde is vervolgens de vaststelling van de aan de Ministers van Binnenlandsche Zaken en Koloniën in te dienen adressen in zake dr. B. F. Matthes.

Naar aanleiding der in de vorige Vergadering daarover gevoerde gedachtenwisseling worden door den heer Kern gewijzigde ontwerpen ter tafel gebracht en voorgelezen. Eenparig vereenigt zich de Vergadering met de hoofdstrekking daarvan, almede ook met eenige daarin voorgestelde wijzigingen en bijvoegingen, waarna wordt goedgekeurd de volgende adressen te richten:

a. aan Zijne Excellentie den Minister van Binnenlandsche Zaken:

"In de overtuiging, dat het belang der wetenschap ook dat van den Staat is en dat Neder!and geroepen is, om in de kennis van de taal-, land- en volkenkunde van den Indischen Archipel niet alleen met vreemde rijken te wedijveren, maar ze te overtreffen, neemt het Koninklijk Instituut voor de taal, land- en volkenkunde van Ned. Indië de vrijheid zich tot Uwe Excellentie te wenden om Uwe aandacht te vestigen op de belangen der studie van de talen van Zuidelijk Celebes, het Makassaarsch en Boegineesch.

Het is bekend, dat weinig talen van den Archipel in rijkdom van letterkundige gewrochten zich met de bovengenoemde kunnen meten en het zou bevreemding kunnen wekken, dat de studie er van betrekkelijk zoo weinig verbreid is, wist men niet tevens hoe lang het duurt vóódat de vaste grondslagen van een nieuw vak van wetenschap gelegd zijn en hoe bezwaarlijk het is eenig vak zonder voorlichting en leiding met vrucht te beoefenen.

Dank zij de onvermoeide werkzaamheid van dr. B. F. Matthes gedurende een dertigjarig verblijf op Celebes zijn de onmisbare grondslagen gelegd. Aau hem toch heeft men te danken eene reeks van werken over de Makassaarsche en lioegineesche taal en letterkunde, belangrijke mededeelingen over de toestauden van land en volk van Zuid-Celebes, die zoozeer worden verduidelijkt door de rijke verzameling van ethnographische voorwerpen, door hem zoo belangeloos aan het Rijks-Museum te Leiden geschonken.

Ontbreekt het derhalve niet aan materieële hulpmiddelen voor de studie, de zoo noodige leiding en het mondeling ouderricht in het Makassaarsch en Boegineesch worden aan de Rijks-Universiteiten ten eenenmale gemist. 
Ware er geen geleerde te vinden, wien men het onderwijs in de meergemelde vakken van wetenschap zou kunnen opdragen, dan zou het Instituut het niet gewaagd hebben de aandacht van Uwe Excellentie op eene, naar zijn gevoelen, bestaande leemte in het Indologisch onderwijs te vestigen. Maar nu dr. Matthes in het vaderland is teruggekeerd en dus van zijne bekwaamheid en talenten partij kan getrokken worden, mag het Instituut niet verzuimen de overtuiging uit te spreken, dat nu de gelegenheid zich als van zelve aanbiedt om de studie van het Makassaarsch en Boegineesch op krachtige wijze te bevorderen

$\mathrm{O}_{p}$ welke wijze zulks het gevoegelijkst en ten oorbaar van den lande geschieden kan, blijve aan het verlicht oordeel van Uwe Excellentie overgelaten.

b. aan Zijne Excellentie den Minister van Koloniën:

„Het zij aan het Koninklijk Instituut voor de taal-, landen volkenkunde van Nederlandsch-Indië vergund zich tot Uwe Excellentie te wenden in het belang eener zaak, waarvan het Instituut zich overtuigd houdt dat zij bij U levendige sympathie wekt.

Voor eenigen tijd is Dr. B. F. Matthes, na zijne hem van regeeringswege opgedragen taak aan de kweekschool voor onderwijzers te Makassar volbracht te hebben, in het vaderland teruggekeerd, in het bezit van rijke materialen voor de taal-, land- en volkenkunde van Zuidelijk Celebes. Bij de bekwaamheid en den ijver, welke de heer Matthes gedurende zijn dertigjarig verblijf op Celebes heeft doen blijken, kan met grond verondersteld worden, dat het ten zeerste in het belang der Indologische wetenschap en dus ook van Nederlandsch-Indië en van den lande zou wezen, indien de talenten en de bouwstoffen van den heer Matthes niet ongebruikt bl ven. Om zich er van te verzekeren, dat de vruchten van zijne veeljarige studie en omvangrijke kennis niet verloren gaan, zou het wenschelijk wezen dat hem, die thans zonder betrekking is, eene bepaalde opdracht werd gegeven ter verwerking van de door hem verzamelde materialen. De aard en omrang van de op te dragen taak, alsmede de wijze, waarop de Staat zich van de diensten van Dr. Matthes verzekeren zal, blijve aan het beleid van Uwe Excellentie overgelaten; het Koninklijk Instituut mag van zijnen kant'de gelegenheid niet laten voorbijgaan om Uwe aandacht te vestigen 
op eene goede zaak, welke het in Uwe belangstelling met vrijmoedigheid en vertrouwen aanbeveelt."

De Vergadering besluit tevens de beide adressen schriftelijk aan de Ministers van Binnenlandsche Zaken en Koloniën in te dienen.

De Secretaris deelt de ontvangst mede van een schrijven van den Graaf Alexandre de Lubasky, te Kiazma, provincie Smolenka, Rusiand, houdende het verzoek om te worden benoemd tot lid van het Instituut.

Voor kennisgeving aangenomen.

De vergadering gaat hierna over tot de benoeming van nienwe leden. De uitslag is dat het lidmaatschap zal worden aangeboden aan de hh.:

Mr. G. van Tienhoven, Lid van de Eerste Kamer der Staten-Generaal, Burgemeester van Amsterdam;

Mr. W. C. Borsius, Lid van de Eerste Kamer der StatenGeneraal, te Middelburg;

Mr. S A. Vening Meinesz. Burgemeester der gemeente Rotterdam;

Mr. O. W. Star Numan, Griffier van de Eerste Kamer der Staten Generaal, te 's Gravenhage :

Jhr. J. D. Six, Referendaris bij het Departement van Koloniën, te 's Gravenhage;

Jhr. Flugi van Aspermont, gep. Kolonel, Chef van den Generalen Staf bij het N.-I. leger, te 's Gravenhage;

F. A. van Braam Houckgeest, Luitenant-Kolonel bij het korps Mariniers, te Nieuwediep;

A. Pompe, Luitenant-Kolonel der infanterie, Eerste officier aau de Kon. Mil. Akademie, te Breda;

P. R. Goudschaal en A. H. L. Badings, Kapiteins der infanterie te Groningen en Amsterdam;

J. A. Kruijt, Consul te Djeddah;

W. J. Pahud de Mortanges, Oud-resident van Krawang, thans te 's Gravenhage;

Mr. A. W. C. Verwey, laatst Officier van Justitie te Padang, thans te Deventer;

Dr. B. Symons, Hoogleeraar in de vergelijkende IndoGermaansche taalwetenschap en het Sanskriet, te Groningen 
Dr. K. Martin, Hoogleeraar directeur der geologischmineralogische afdeeling van het Museum voor natuurlijke historie te Leiden;

Dr. M. T'h. Houtsma, Adjutor Interpretis Legati Warneriani, te Leiden;

Dr. W. Pleyte, Conservator van het Museum van Oudheden, te Leiden;

B. Heldring, Directeur der Nederlandsche Handelmaatschappij, te Amsterdam;

J. Wuste, Lid der firma Wuste en Hintzen, te Amsterdam;

Mr. H. Hope Loudon, te 's Gravenhage;

Mr. A. F. Heijligers, Hoofdredacteur van het Vaderland, te 's Gravenhage;

Mr. J. W. Tydeman Jr., Secretaris van de Vereeniging voor Suriname, te Amsterdam;

N. W. Posthumus, Directeur van de Hoogere Burgerschool met 3 jarigen cursus, Secretaris van het Aardrijkskundig Genootschap, te Amsterdam;

P. A. M. Boele van Henebroek, Lid der firma Mart. Nijhoff en Co., te 's Gravenhage.

Tot correspondeerend lid wordt benoemd de heer P. A. Tiele, Bibliothecaris der Universiteits Bibliotheek te Utrecht; en

tot buitenlandsche leden de hh.:

Dr. A. B. Meijer, Nirecteur van het Kon. Zoölogisch Museum, te Dresden; L. M. Albertis en Prof. O. Beccari, te Florence.

Van deze benoemingen zal aan de Algemeene Vergadering worden kennis gegeven.

Naar aanleiding van een door den Secretaris ontvangen briefkaart van het lid Scheltema uit Haarlem wordt medegedeeld, dat het late uur der bijeenkomst voor de Algemeene Vergadering voor velen eene verhindering is om haar bij te wonen. Wordt besloten tegen de volgende Algemeene Vergadering in overweging te nemen of het niet mogelijk zou zijn vroeger bij een te komen.

Niets meer hierna aan de orde zijnde, wordt de Vergadedoor den Voorzitter gesloten. 